\title{
An integrative genomic analysis revealed the relevance of microRNA and gene expression for drug-resistance in human breast cancer cells
}

\author{
Yusuke Yamamoto 1,2,4, Yusuke Yoshioka 1,2,4, Kaho Minoura ${ }^{3}$, Ryou-u Takahashi', Fumitaka Takeshita', Toshiki Taya ${ }^{3}$,
} Reiko Horii ${ }^{3}$, Yayoi Fukuoka ${ }^{3}$, Takashi Kato ${ }^{2}$, Nobuyoshi Kosaka ${ }^{1}$ and Takahiro Ochiya ${ }^{1 *}$

\begin{abstract}
Background: Acquisition of drug-resistance in cancer has led to treatment failure, however, their mechanisms have not been clarified yet. Recent observations indicated that aberrant expressed microRNA (miRNA) caused by chromosomal alterations play a critical role in the initiation and progression of cancer. Here, we performed an integrated genomic analysis combined with array-based comparative hybridization, miRNA, and gene expression microarray to elucidate the mechanism of drug-resistance.
\end{abstract}

Results: Through genomic approaches in MCF7-ADR; a drug-resistant breast cancer cell line, our results reflect the unique features of drug-resistance, including MDR1 overexpression via genomic amplification and miRNA-mediated TP53INP1 down-regulation. Using a gain of function study with 12 miRNAs whose expressions were downregulated and genome regions were deleted, we show that miR-505 is a novel tumor suppressive miRNA and inhibits cell proliferation by inducing apoptosis. We also find that Akt3, correlate inversely with miR-505, modulates drug sensitivity in MCF7-ADR.

Conclusion: These findings indicate that various genes and miRNAs orchestrate to temper the drug-resistance in cancer cells, and thus acquisition of drug-resistance is intricately controlled by genomic status, gene and miRNA expression changes.

Keywords: aCGH, microRNA, gene expression, breast cancer, drug resistance

\section{Background}

Systemic therapy improves disease-free survival in patients with breast cancer, but does not cure patients with advanced or metastatic disease, and fails to benefit the majority of patients with localized breast cancer. Intrinsic resistance to chemotherapy is emerging as a significant cause of treatment failure, and evolving research has identified several potential causes of resistance [1]. For instance, P-glycoprotein (Pgp), the drug efflux pump encoded by the MDR- 1 gene is associated with multidrug resistance in several kinds of advanced cancer. Furthermore, the multidrug resistance-associated protein MRP1 $[2,3]$, breast cancer resistance protein (ABCG2) and other

\footnotetext{
* Correspondence: tochiya@ncc.go.jp

'Division of Molecular and Cellular Medicine, National Cancer Center Research Institute, 1-1, Tsukiji, 5-chome, Chuo-ku, Tokyo 104-0045, Japan Full list of author information is available at the end of the article
}

transporters [4], which act as energy-dependent efflux pumps capable of expelling a large range of xenobiotics, have been reported to be upregulated in tumor cells showing the multidrug-resistant phenotype. In addition, overexpression of anti-apoptotic proteins, such as Bcl-2 and $\mathrm{Bcl}-\mathrm{xL}$, are also associated with drug resistance and poor clinical outcome in cancer patients. It is essential to decide the molecular target to treat the advanced cancer by molecular targeted therapies such as RNA interference and antibody treatment, however, regulatory networks underlying drug resistance in cancer cells have been elusive.

MicroRNAs (miRNAs) are small non-coding RNA of 21-25nt transcripts, playing central roles in physiological and pathological processes, including cell differentiation, apoptosis, and oncogenesis by either inducing mRNA degradation or by regulating the translational efficiency of mRNA [5-7]. Recently, several research groups have

\section{Biomed Central}


provided evidence that some miRNA expression levels are frequently modulated by genomic aberrations, such as genomic DNA copy number gain or loss, translocations, and epigenetic regulations [8]. For example, miR$15 \mathrm{a}$ and miR-16-1, whose genomic regions are deleted and expressions are down-regulated in the majority of chronic lymphocytic leukemia (CLL). Furthermore, their target Bcl-2 is overexpressed in CLL at the mRNA and protein level [9]. Another study showed that the expression level of miR-34a was down-regulated by deletion of 1 p36 heterozygosity in neuroblastoma and contributed to an aggressive phenotype [10]. As reported in the studies of cancer genetics in lung, leukemia, colon, breast and ovary, a large number of miRNAs are located at chromosomal fragile sites, i.e., minimal regions of loss of heterozygosity $(\mathrm{LOH})$ and minimal regions of genomic amplification [11]. These reports indicated that the emphasis on a genomic analysis was due to the fact that DNA copy number alterations are associated with expression levels of miRNAs and genes.

In this study, to better understand the regulatory network underlying drug resistance in breast cancer cells, we focus on miRNAs and genes located on the genomeamplified and -deleted regions because genomic aberration is closely associated with gene expression, and this expression alteration might be constantly maintained. For the identification of molecular targets, we initially performed an integrated genomic analysis to compare the DNA copy number and expression profile of mRNA and miRNA between MCF7; a parental breast cancer cell line and MCF7-ADR; a drug-resistant breast cancer cell line $[12,13]$. Through the genomic analysis, we found that the genomic alterations of drug resistance-related genes, e.g. amplified genomic regions and overexpression of MDR-1 and miRNA-mediated TP53INP1 down-regulation. In addition, of 12 miRNAs whose expressions were downregulated and genomic regions were deleted, we determined that miR-505 promotes the inhibition of cell growth in MCF7-ADR cells, by inducing apoptotic cell death in the presence of docetaxel (DOC).

\section{Methods}

\section{Cell culture}

MCF7 human mammary carcinoma cells and multidrugresistant MCF7-ADR human mammary carcinoma cells were obtained from Shien-Lab, Medical Oncology, National Cancer Center Hospital. MCF7-ADR-Luc cells were established by transfecting with a pLuc-neo expression vector, which has the firefly luciferase GL3 cDNA cloned into the downstream of the SV40 promoter and the G418 selective marker gene. Cells were selected in a medium containing $0.6 \mathrm{mg} / \mathrm{ml}$ of G418 (Gibco BRL) and were maintained and passaged in an RPMI 1640 medium (Gibco BRL) supplemented with 10\% fetal bovine serum
(Gibco BRL) under $5 \% \mathrm{CO}_{2}$ in a humidified incubator at $37^{\circ} \mathrm{C}$.

\section{RNA and genomic DNA extraction}

Total RNA was extracted from MCF7, MCF7-ADR, and MCF7-ADR-Luc cells using the ISOGEN solution (Nippon Gene, Tokyo, Japan) according to the manufacturer's protocol. Genomic DNA was prepared from MCF7 and MCF7-ADR. The yield and purity of the genomic DNA and total RNA were measured using a NanoDrop ND1000 spectrophotometer (Thermo Fisher Scientific). The quality of the total RNA was verified to have an RNA Integrity Number using a Bioanalyzer and RNA 6000 LabChip Kit (Agilent Technologies).

\section{Oligonucleotide array CGH (aCGH) Analysis}

All DNA labeling reactions and hybridizations were carried out following the manufacture's protocol (Agilent Oligonucleotide Array-Based CGH for Genomic DNA Analysis, Version 4.0, Direct Method). Briefly, $3.0 \mu \mathrm{g}$ of MCF-7, MCF7-ADR and reference DNA (Promega, female, p/n G1521) were digested with AluI and RsaI for 2 hours at $37^{\circ} \mathrm{C}$, followed by heat inactivation at $65^{\circ} \mathrm{C}$ for 10 minutes. Digested DNA was then labeled using the Agilent Genomic DNA Labeling Kit Plus (p/n 5188-5309) using random primers and the exo-Klenow fragment to differentially label genomic DNA samples with fluorescently labeled nucleotides. All experimental and reference samples were labeled with Cyanine- 5 dUTP and Cyanine3 dUTP, separately, for 2 hours at $37^{\circ} \mathrm{C}$ to enable duplicate hybridizations with the corresponding dye reversal arrays. Experimental and reference targets for each hybridization were purified with a Microcon YM-30 column (Millipore) and validated by the NanoDrop ND-1000, respectively to ensure the yield and the specific dye incorporation activity of the labeled genomic DNA. The individual pair of labeled targets were combined together, mixed with Cot-1 DNA (Invitrogen) and 10xBlocking Agent (Agilent), and then mixed with Agilent 2xHybridization Buffer $(\mathrm{p} / \mathrm{n}$ 5188-5220). Before hybridization, the combined mixtures were denatured for 3 minutes at $95^{\circ} \mathrm{C}$, incubated for 30 minutes at $37^{\circ} \mathrm{C}$ and then applied to the Agilent Human 244A CGH arrays (G4411B). Using an Agilent microarray hybridization chambers, the hybridization was carried out for 40 hours at $65^{\circ} \mathrm{C}$ in a rotating oven (Agilent) at 20 r.p.m. The hybridization chambers were then disassembled and array slides were washed for 5 minutes at room temperature in Agilent Oligo aCGH Wash Buffers 1 , followed by 1 minute at $37^{\circ} \mathrm{C}$ in Agilent Oligo aCGH Wash Buffer 2 (p/n 5188-5226) (prewarmed to $37^{\circ} \mathrm{C}$ overnight). The slides were removed from the wash buffer 2 slowly (5-10 seconds) after which time they were completely dry and were scanned using an Agilent DNA Microarray scanner with $5 \mu \mathrm{m}$ resolution. The data of microarray 
images were extracted by Agilent Feature Extraction Software v9.5 in which a modified Feature Extraction protocol, CGH-v4_95_Feb07 was used in conjunction with a gene list on chromosome $21 \mathrm{q}$-arm to normalize spot-intensity values and ratios to each extraction set. These ratio data along with associated error values and flagged features were imported into CGH Analytics Software v3.4 (Agilent). The dye reversal data and intra-replicate spots were then combined while the data centralization and fuzzy zero algorithms were not applied in the CGH Analytics. To make aberration calls, an aberration detection algorithm, ADM-2 [14] was used at threshold 10 and an aberration filter was set at 2 for the minimum number of probe region and 1 for minimum absolute average log2 ratio for regions in the $\mathrm{CGH}$ Analytics to reduce false positives.

\section{Gene Expression Analysis}

All RNA labeling reactions and hybridizations were carried out following the manufacture's protocol (Agilent OneColor Microarray-Based Gene Expression Analysis, Version 5.0.1). Briefly, polyA(+)RNA in $500 \mathrm{ng}$ of total RNA was primed with an oligo (d)T-T7 primer and converted into dsDNA with MMLV-RT, then transcribed and simultaneously labeled with Cyanine 3-CTP for 2 hours at $40^{\circ} \mathrm{C}$ using Agilent Low RNA Input Linear Amplification Kit (p/n 5188-5339). After labeling and cRNA purification, cRNA was quantified and the specific dye incorporation activity was validated using the NanoDrop ND-1000. 1.65 $\mu \mathrm{g}$ of labeled cRNA was mixed with Agilent $10 \times$ Blocking Agent and $25 \times$ Fragmentation Buffer, then incubated at $60^{\circ} \mathrm{C}$ for 30 hours. After fragmentation, the cRNA mixtures were immediately mixed with Agilent $2 \times$ Hybridization Buffer (p/n 5188-5339) and applied to the Agilent Human $4 \times 44 \mathrm{~K}$ whole genome microarrays (G4112F) for 17 hours at $65^{\circ} \mathrm{C}(10$ r.p.m.). Array slides were washed with Agilent Gene Expression Wash Buffer 1 and 2 (p/n 5188-5327) and then scanned using the Agilent DNA Microarray scanner with $5 \mu \mathrm{m}$ resolution and the eXtended Dynamic range setting (XDR Hi 100\%, Low $10 \%)$ to avoid saturated features. The data of microarray images were extracted by Agilent Feature Extraction Software v9.5 using the GE1_v5_95 protocol. The extracted signal intensities and flagged information were imported into GeneSpring 7.3.1 software and the data sets were normalized by adjusting the intensity distribution of wellabove background and unflagged features to 50th percentile to account for the interchip variability. Comparison of MCF7 and MCF7-ADR was done using duplicate array data set for each cell line.

\section{miRNA Expression Analysis}

All RNA labeling reactions and hybridizations were carried out following the manufacture's prototype protocol
(Agilent miRNA Microarray system, Version 0.3, early access). Briefly, $100 \mathrm{ng}$ of total RNA including fraction of small mature miRNA was dephosphorylated by calf intestine alkaline phosphatase (p/n E2250Y, Amersham Biosciences) for 30 minutes at $37^{\circ} \mathrm{C}$ and denatured by adding DMSO (p/n D8418, Sigma) for 8 minutes at $100^{\circ} \mathrm{C}$. Ligation was then carried out with T4 RNA ligase $(\mathrm{p} / \mathrm{n}$ E2050Y, Amersham Biosciences) and pCp-Cy3 (p/n 5190-0408, Agilent) for 2 hours at $16^{\circ} \mathrm{C}$ that allowed us to perform a quantitative direct labeling method [15]. The labeled miRNAs were desalted with Micro Bio-Spin 6 column (p/n 732-6221, Bio-Rad) and combined with Agilent $10 \times$ GE Blocking Agent and $2 \times$ Hybridization Buffer (p/n 5190-0408). The mixture was heated for $5 \mathrm{~min}-$ utes at $100^{\circ} \mathrm{C}$ and immediately cooled to $0^{\circ} \mathrm{C}$. Each sample was hybridized to the Agilent early access Human $8 \times 15 \mathrm{~K}$ microRNA microarrays covered 470 miRNAs (AMADID 015508, early access) for 20 hours at $55^{\circ} \mathrm{C}$ (20 r.p.m.). Array slides were washed with $6 \times \mathrm{SSC} /$ $0.005 \%$ Triton $\mathrm{X}-100$ for 10 minutes, then $0.1 \times \mathrm{SSC} /$ $0.005 \%$ Triton X-100 for 5 minutes, both at room temperature. Slides were scanned using the Agilent DNA Microarray scanner with $5 \mu \mathrm{m}$ resolution and the eXtended Dynamic range setting (XDR Hi 100\%, Low $5 \%)$ to avoid saturated features. The data were extracted by Agilent Feature Extraction Software v9.5 using the miRNA_120106 protocol which extracts intensities of multiple probes with multiple features per probe and reports the measurements and errors as the TotalGeneSignal and TotalGeneSignalError for each of the miRNAs. These values were imported to the GeneSpring GX version 7.3.1 without applying any normalization algorithm. The miRNA profiles generated on the Agilent platform were prior normalized to the amount of input total RNA in which $100 \mathrm{ng}$ of total RNA were equally used for each assay and all of the labeled targets were loaded on each array. Comparison of MCF7 and MCF7ADR was done using duplicate array data set for each cell line.

\section{Transfection of miRNA into MCF7-ADR-Luc cells}

For MCF7-ADR-Luc cells, transfection of miRNA was carried out using DharmaFECT 1 (Dharmacon) according to the manufacturer's protocol. MCF7-ADR-Luc cells were plated in growth medium 24 hours before transfection. The cells, which were grown to $50 \%$ confluence, were transfected with $20 \mathrm{nM}$ miRNAs and cultured. Two or 3 days after transfection, the cells were subjected to further analyses.

Apoptosis assay measurement of caspase activity in vitro Caspase-7, which plays key effecter roles in apoptosis, was detected in caspase-3-deficient MCF7-ADR-Luc cells. The arrays used in an in vitro growth assay were 
measured with the Apo-ONE Homogeneous Caspase-3/ 7 Assay (Promega) according to the manufacturer's instructions. Cells were incubated with the Apo-ONE Caspase-3/7 Assay Reagent for 1.5 hours at room temperature, and the fluorescence was then measured at 485Ex/535Em with a Wallac Multi-label Counter.

\section{Hoechst staining}

Cells were washed with PBS(-), and a fixative and staining solution was added (4\% paraformaldehyde, $1 \mu \mathrm{g} / \mathrm{ml}$ Hoechst 33342 in PBS). Ten minutes after incubation, cells were washed with PBS, and the number of apoptotic cells was then determined in three microscopic fields of each well by fluorescence microscopy (Olympus).

\section{Luciferase assay for the measurement of cell growth}

MCF7-ADR-Luc cells were plated into $5 \times 10^{3}$ cells per well and cultured. The cell growth in each well was then estimated by firefly luciferase activity because the cell numbers were correlated with the bioluminescence from MCF7-ADR-Luc cells. Luciferase assays were performed with a Wallac Multi-label Counter (PerkinElmer) and Bright-Glo Luciferase Assay System (Promega, Tokyo, Japan) according to the manufacturer's protocol.

\section{Real-time RT-PCR}

The total RNA was used to produce cDNAs with the SuperScript ${ }^{\mathrm{TM}}$ II First-Strand Synthesis System (Invitrogen, Tokyo, Japan) according to the manufacturer's protocol. For quantification, cDNA samples were subjected to realtime PCR using Platinum SYBR Green qPCR SuperMix UDG (Invitrogen) in triplicates, and reactions were carried out in an ABI PRISM 7300 (Applied Biosystems, Tokyo, Japan). The specific sequences of primers for the analyzed genes are shown in Additional File 1 Table S1. The expression levels of genes were normalized to GAPDH. For miRNA real-time RT-PCR, total RNAs of approximately 100 ng were reverse-transcribed using the Taqman miRNA reverse transcription kit (Applied Biosystems). Real-time quantitative PCR amplification of the cDNA template was done using Taqman Universal PCR Master Mix (Applied Biosystems, Tokyo, Japan) in an ABI PRISM 7300 (Applied Biosystems). The PCR conditions were $50^{\circ} \mathrm{C}$ for 2 minutes and $95^{\circ} \mathrm{C}$ for 10 minutes followed by 50 cycles of $95^{\circ} \mathrm{C}$ for 15 seconds and $60^{\circ} \mathrm{C}$ for 1 minute. Taqman probes for human were used to assess the expression levels of miRNAs (hsa-miR-505, ID: 4373230, hsamiR-130, ID: 000454, and hsa-miR-155, ID: 002623).

\section{3'UTR assay plasmid constructs}

A 1235 bp fragment from the 3'UTR of Akt3 containing the predicted target sequence of miR-505 (located at positions 529-535 of the Akt3 3'UTR) and a 934 bp fragment from the 3'UTR of Akt3 containing the predicted target sequence of miR-505 (located at positions 529-535 of this fragment) were PCR-cloned from MCF7-ADR cells isolated total RNA. Three prime A-overhang was added to the PCR products after 15 minutes of regular Taq polymerase treatment at $72^{\circ} \mathrm{C}$. The PCR products were cloned into a pGEM-T easy vector (Promega). The amplified products were ligated into the NotI sites of the 3'UTR of the Renilla luciferase gene in the psi-check-2 plasmid (Promega) to generate psi-Akt3_1 (1235 bp) and psi-Akt3_2 (934 bp). Primer sequences used for PCR-cloning were shown as below: Akt3_F, GAGCCAGAGAGCATCT TTCC, Akt3_R1, GCTGCCTTAGTAAAATGCCC, and Akt3_R2, GACTTCACAGGCTGCTTTGG.

\section{Statistical analysis}

The results are given as the mean \pm s.d. Statistical analysis was conducted using the analysis of variance with the Student's t-test. A $P$ value of 0.05 or less was considered to indicate a significant difference.

\section{Results}

\section{An integrated genomic analysis unveils the status of} cancer cells

MCF7-ADR is a multi-drug resistant cell line derived from MCF7 breast cancer cell line. We utilized these two cell lines to understand the regulatory network underlying drug resistance in breast cancer and conducted three types of genomic analysis, i.e. array-based comparative hybridization $(\mathrm{aCGH})$ (Figure $1 \mathrm{~B})$, miRNA (Additional File 2 Figure. S1A) and gene expression (Additional File 2 Figure. S1B). Genes and miRNAs, which are located on the genome-amplified and -deleted regions, are expected to be responsible for drug resistance and sensitivity. Moreover, these three types of array data were used for miRNA target prediction and pathway to further elucidate key factors for drug resistance (Figure 1A).

As a consequence of array-based $\mathrm{CGH}$, changes in DNA copy number in MCF7-ADR and MCF7 as compared with normal female genome were found in a large number of regions as amplification and deletion (Figure 1B). Accuracy of array-based CGH was validated by dye flip experiment that exhibited strikingly mirroring images (Additional File 3 Figure. S2). The numbers of genes and miRNAs located on the amplified and deleted genome regions (fold change > 3) in MCF7-ADR and MCF7 cells are shown (Figure $1 C)$. On further comparison, a large number of changes in gene and miRNA expressions were observed between MCF7 and MCF7-ADR (Additional File 2 Figure. S1A and B). These genes with aberrant differences were observed predominantly in amplified region in MCF7 and, in contrast, they were mainly in deleted regions in MCF7-ADR (Figure $1 \mathrm{~B}$ and $1 \mathrm{C}$ ). In a different criterion of aCGH data (fold change $>2$ ), we could see the same propensity more clearly (Additional File 4 Figure. S3A and B). 


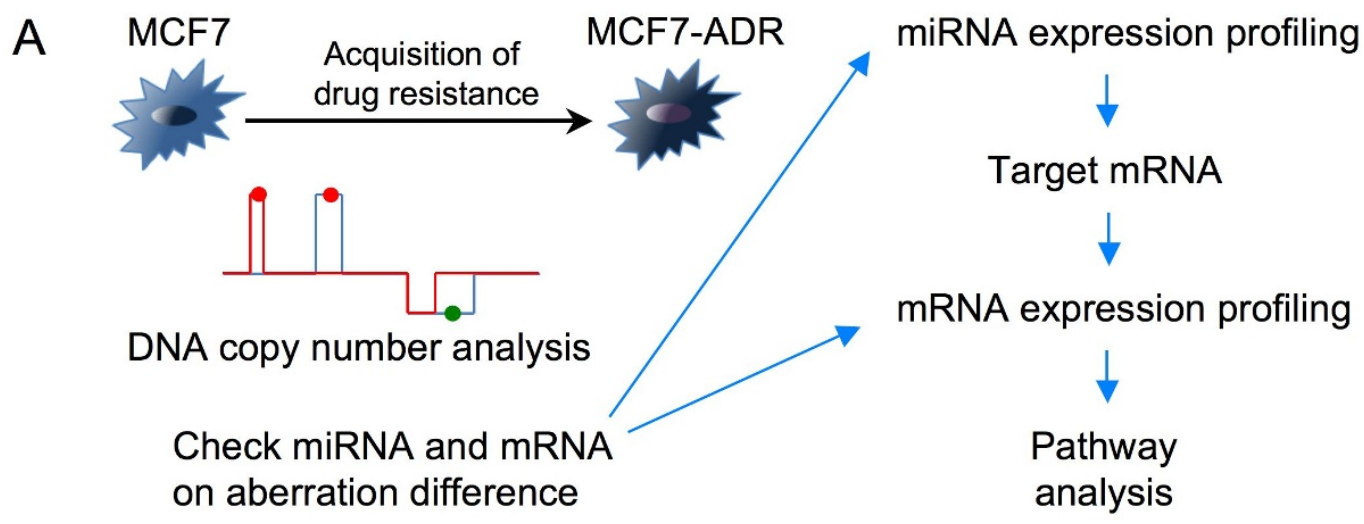

B

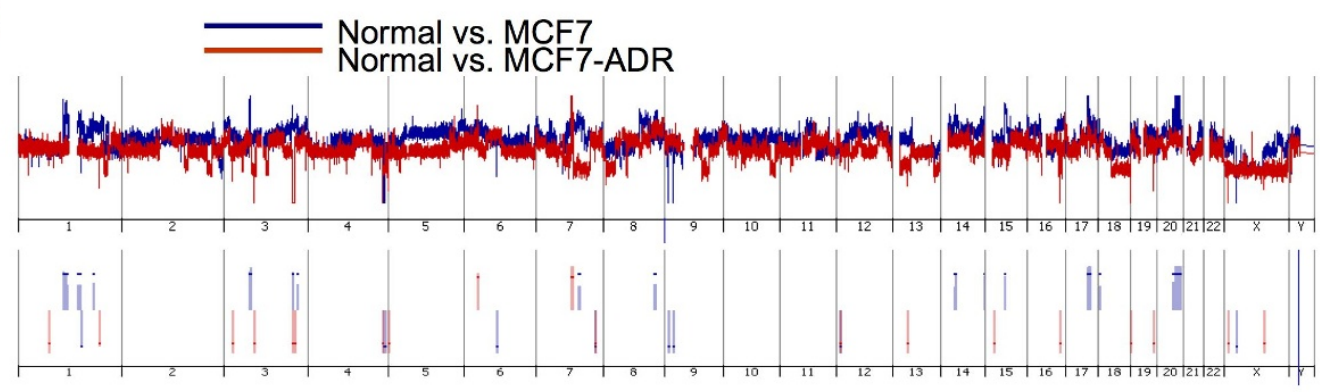

C

\begin{tabular}{crrrrrr} 
DNA copy & \multicolumn{2}{c}{ MCF7 } & & \multicolumn{2}{c}{ MCF7-ADR } \\
\cline { 2 - 3 } \cline { 5 - 6 } Number & Gene & miRNA & & Gene & miRNA \\
\cline { 1 - 2 } Amp & 426 & 7 & & 6 & 0 \\
Del & 6 & 0 & & 25 & 1 \\
\hline
\end{tabular}

D 426 genes
on MCF7 amp regions

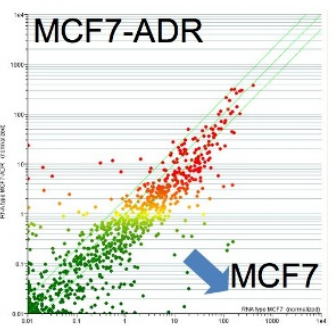
on MCF7 del regions

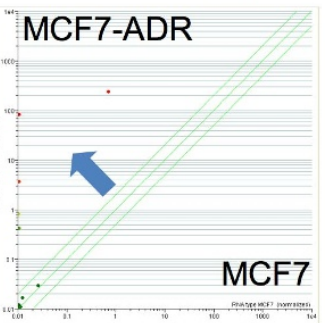

$\mathrm{E}$ on MCF7-ADR amp regions on MCF7-ADR del regions
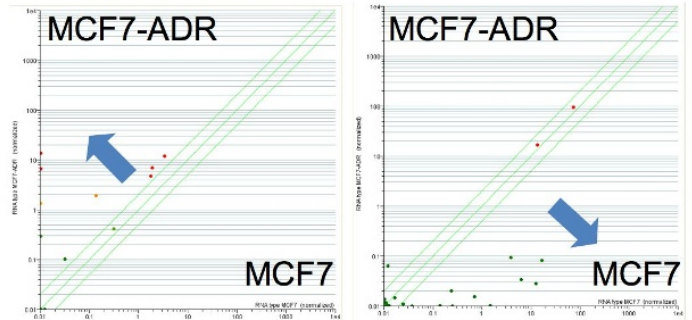

Figure 1 An integrated genomic analysis to clarify drug resistance in MCF7-ADR (drug-resistant breast cancer cell line). (A) Schematic representation of an integrated genomic analysis. During the acquisition of drug resistance in breast cancer cell (MCF7; parental cell line and MCF7-ADR; drug resistance cell line), a large number of genomic alterations were raised, such as amplification or deletion, to modulate the expression of genes and miRNAs. Based on aCGH, miRNAs and genes on the aberration region of genome are selected for further analysis of its target genes and their associated-pathways in silico. (B) aCGH analysis of MCF7 and MCF7-ADR as compared with normal human female genome. Blue line shows normal vs. MCF7, and red line shows normal vs. MCF7-ADR (top). Amplified or deleted genome regions (fold change > 3) are highlighted (bottom). (C) The numbers of genes and miRNAs located on the amplified or deleted genome regions (FC $>3$ ). (D and E) The expression tendency of genes located on the aberrant genome regions. 426 genes from MCF7 amplified regions and 6 genes from MCF7-ADR amplified regions are plotted in left panels of each scatter plot. Six genes from MCF7 deleted regions and 25 genes from MCF7-ADR deleted regions are plotted in right panels of each scatter plot. 
Because genomic amplification and deletion are thought to be associated with up- and down-regulation in expression, respectively, 426 genes on the amplified region in MCF7 and 6 genes on the deleted regions in MCF7 were plotted (Figure 1D). When the expression levels of amplified 426 genes and deleted 6 genes were checked, the expression of 426 genes tended to increase (Figure 1D left), and vice versa that of 6 genes tended to decrease in MCF7 as compared with MCF7-ADR (Figure $1 \mathrm{D}$ right), although these gene numbers were counted based on the comparison of MCF7 and normal female genome. Consistent with MCF7 result, we can see similar tendency in gene expression in the result of MCF7-ADR (Figure 1E), indicating that the gene expression levels and genomic alterations are broadly correlated in this experiment.

\section{An integrated genomic analysis reflects the unique features of drug resistance in breast cancer cells}

We hypothesized that genes and miRNAs in the region of genomic alteration were relevant to drug resistance in MCF7-ADR cells. In the most amplified region in MCF7ADR, we found MDR1 gene, which is an important efflux pump for drug resistance. Its genome locus was amplified more than 20-fold (Figure 2A), and its expression was upregulated 800 -fold or more in MCF7-ADR by microarray (Figure 2B). Expression level of MDR1 was confirmed by real-time RT-PCR and was observed to be remarkably upregulated in MCF7-ADR consistent with our previous study (Figure 2C) [13], suggesting that the genomic amplification and overexpression of MDR1 were one of the reasons for drug resistance of MCF7-ADR.

Next, we tried to know the target genes of differentiallyexpressed miRNA in MCF7-ADR, because these genes might act as key molecules for drug resistance. Seventyfour miRNAs were 2 fold or more up-regulated in MCF7ADR (Figure 3A), and we selected genes that have binding sites of more than $15 \%$ of up-regulated miRNAs in their 3'UTR. The scatter plot shows expression levels of these genes (Figure 2D), and 3 gene names are displayed because their expression levels are considerably downregulated in MCF7-ADR. One of them is tumor protein p53 inducible nuclear protein 1 (TP53INP1) (Figure 2D), which has been recently shown to be suppressed by several miRNAs such as miR-130 and miR-155 [16,17]. Furthermore, decreased expression of TP53INP1 is involved in breast cancer progression [18]. As shown in Figure 2E, expression of miRNAs which potentially bind to 3'UTR of TP53INP1 were plotted, and it displays names of miRNAs whose expression levels were considerably up-regulated in MCF7-ADR. These included miR-130 and miR-155 also known as TP53INP1 binding miRNAs, and most of them are highly expressed in MCF7-ADR, indicating that these miRNAs and TP53INP1 expressions were inversely correlated. From the real-time RT-PCR analysis, downregulation of TP53INP1 and up-regulation of miR-130 and miR-155 in MCF7-ADR as compared with MCF-7 (Figure $2 \mathrm{~F}$ and $2 \mathrm{G}$ ). Taken together with our results and recent publications, our integrated genomic analysis can clearly reflect the status of multi-drug resistant MCF7ADR.

\section{Pathway analysis of up- and down-regulated miRNA target genes}

Cancer cells abrogate the function of drug sensitive genes, such as tumor suppressor gene and related-gene pathway after the anticancer drug treatment, and thus we speculated that differentially-expressed miRNAs between MCF7-ADR and MCF7 controlled the gene pathway governing drug resistance. As shown in Figure 3A, 74 miRNAs and 32 miRNAs were up- and down-regulated in MCF7-ADR, respectively. Target gene prediction showed up-regulated 74 miRNAs had 5, 137 genes and downregulated 32 miRNAs had 3, 579 genes as target candidates (Figure 3A). Expression levels of these genes were plotted in the scatter plots, however, decreasing and increasing expression tendencies were not clearly observed (data not shown). So, with these genes, we next checked what kind of gene pathways were expected to be regulated by differentially-expressed miRNAs. A large number of pathways were significantly chosen (Top 20 pathways shown in Additional File 5 Table S2). Surprisingly, many common pathways were enriched in both up-and downregulated miRNA targeted genes, suggesting that the differentially-expressed miRNAs orchestrated to lead the global gene expression changes in MCF7-ADR. Intriguingly, these miRNAs seem to regulate some of drug resistance related signaling pathways, such as Wnt, insulin, EGFR1, MAPK and TGF-beta receptor (Additional File 5 Table S2, Figure. 3B and Additional File 6 Figure. S4). This data shows the possibility that differentially-expressed miRNAs might cooperatively regulate their target pathways and change drug resistance and sensitivity in MCF7-ADR.

\section{Identification of miRNAs that suppress cell proliferation in MCF7-ADR}

We next explored whether the miRNAs that were located on the aberrant genome regions played a role in regulating drug resistance of MCF7-ADR. To this end, genomic status between MCF7-ADR and MCF7 were directly compared (Figure 4A). The numbers of genes and miRNAs that were located on the aberrant regions are shown (Figure $4 B$ ) and most of them were on the deleted regions in MCF7-ADR. A scatter plot showed 49 miRNAs on the deleted genomic regions in MCF7-ADR (Figure 4C) and expression levels of these 49 miRNAs had decreasing trend in MCF7-ADR. In this study, we focus on miRNAs whose expressions were down-regulated and genomic 
A

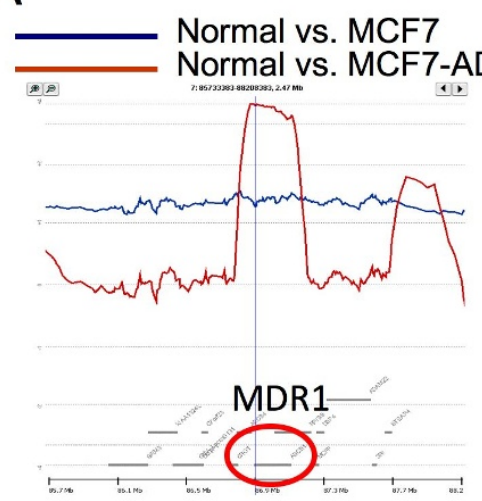

$\mathrm{D}$

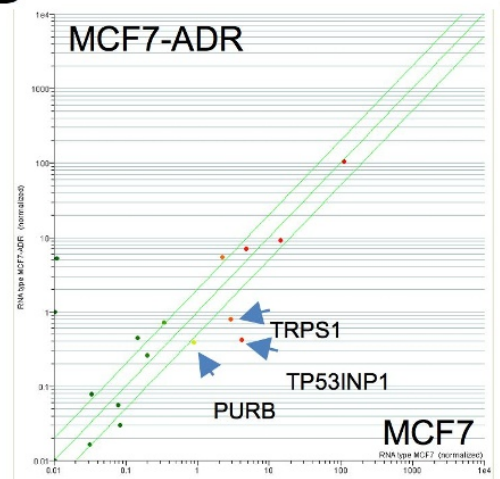

G

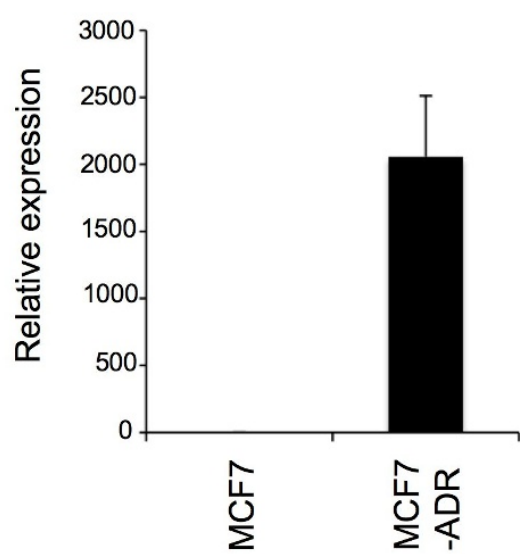

B

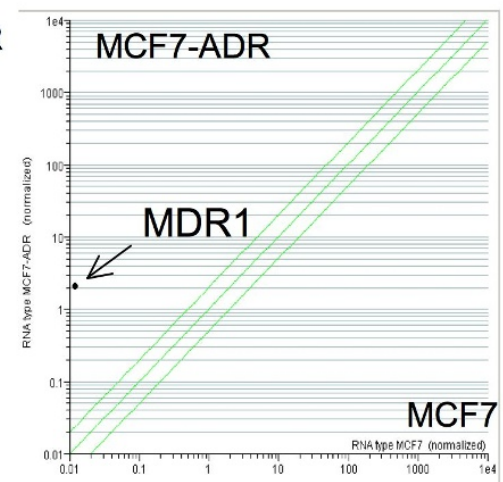

$\mathrm{E}$

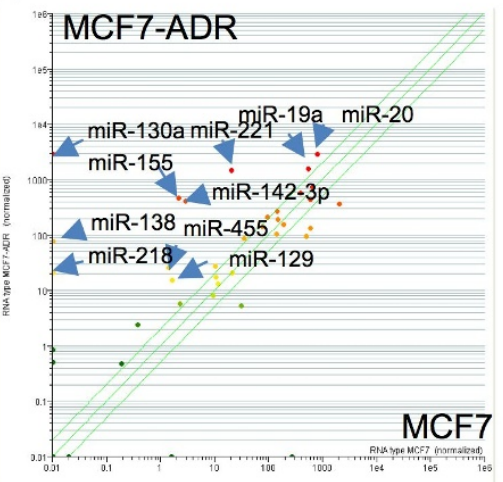

\section{$\operatorname{miR}-155$}

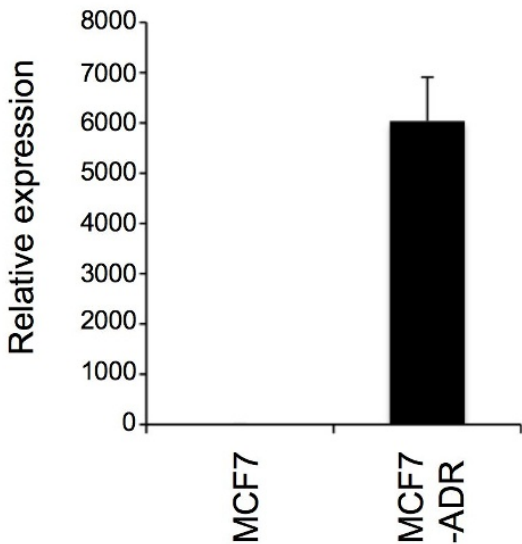

Figure 2 Genomic amplification and overexpression of MDR1, and a number of miRNA regulation of TP53INP1. (A) Twenty fold amplification of multi-drug resistance gene (MDR1) region in MCF7-ADR as compared with MCF7. (B and C) Overepression of MDR1 gene in MCF7-ADR by microarray and real-time PCR, respectively. (D) Scatter plot of miRNA target genes predicted by Targetscan. More than 15\% of miRNAs up-regulated in MCF7-ADR (74 miRNAs) were predicted to potentially bind the 3'-UTR of these genes. Expression levels of three (TP53INP1, PURB and TRPS1) of them are clearly dwon-regulated. (E) Scatter plot of miRNAs that might bind to 3'UTR of TP53INP1 gene. (F and G) Confirmation of TP53INP1 gene, miR-130 and miR155 expression by real-time PCR. Standard deviation was calculated in triplicate determinants in the experiment. 
A
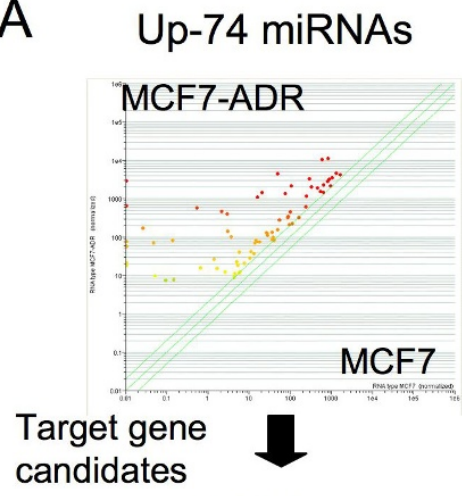

5,137 genes
Down-32 miRNAs

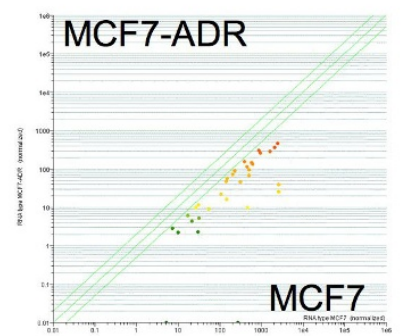

3,579 genes

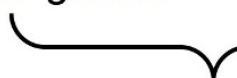

Pathway

analysis

B

\section{Wnt signaling pathway}

74 Up miRNAs - target genes

WNT4

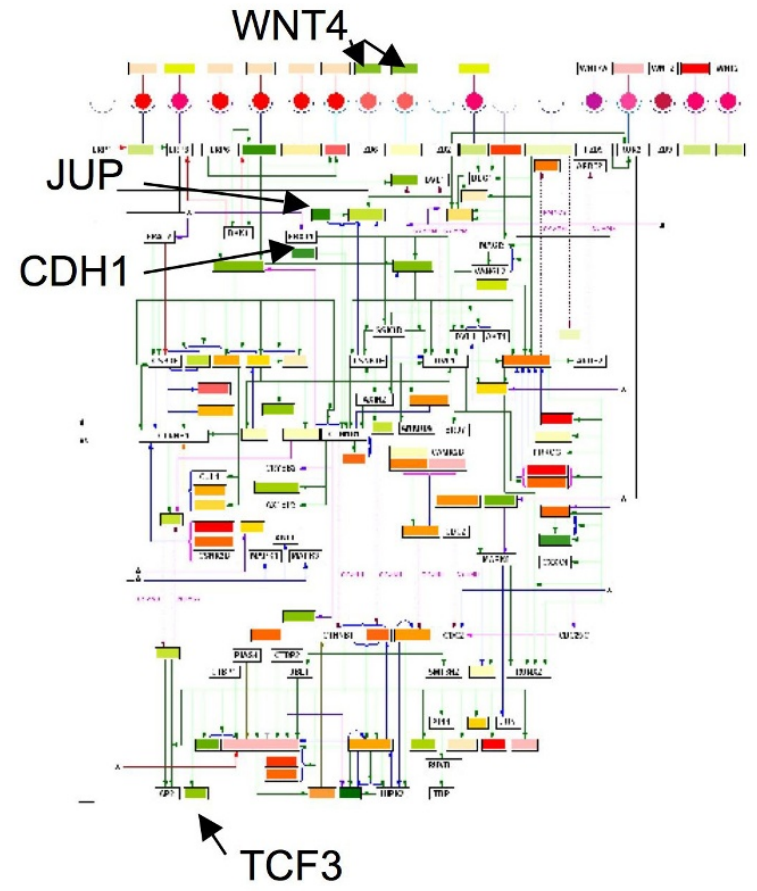

32 Down miRNAs - target genes

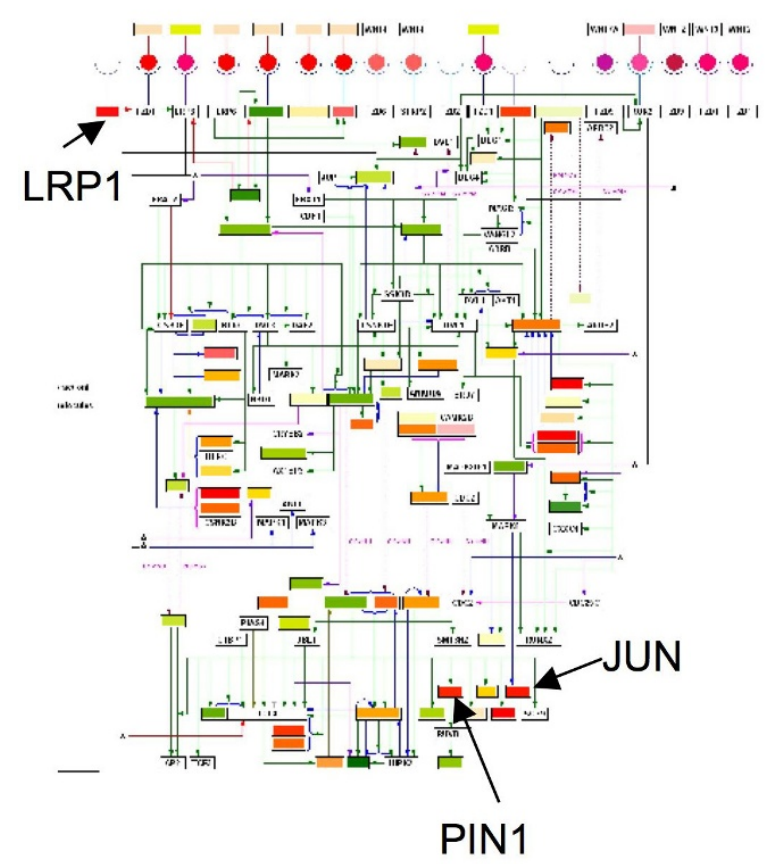

Figure 3 Pathway enrichment analysis of up- and down-regulated miRNAs in breast cancer cells. (A) Diagram of GO analysis of MCF7 and MCF7-ADR. In the comparison with MCF7 and MCF7-ADR, 5, 137 genes and 3, 579 genes are predicted as miRNA target candidates of 74 upregulated miRNAs and 32 down-regulated miRNAs, respectively. With these predicted genes, enriched pathways are selected, as shown Table S1. (B) Wnt signaling pathway. 74 miRNA-targeted genes are plotted in Wnt signal pathway map (left), 32 miRNA-targeted genes are plotted (right). Red boxes show high expression genes, and green boxes show low expression genes. 
A MCF7-ADR minus MCF7

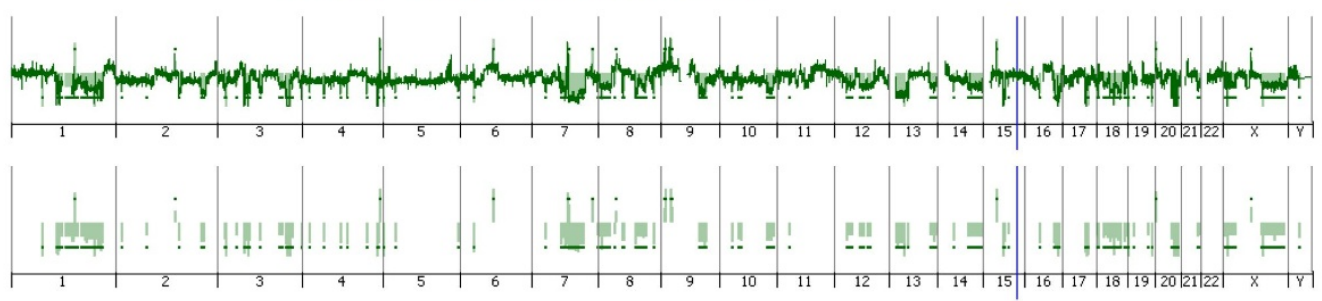

B

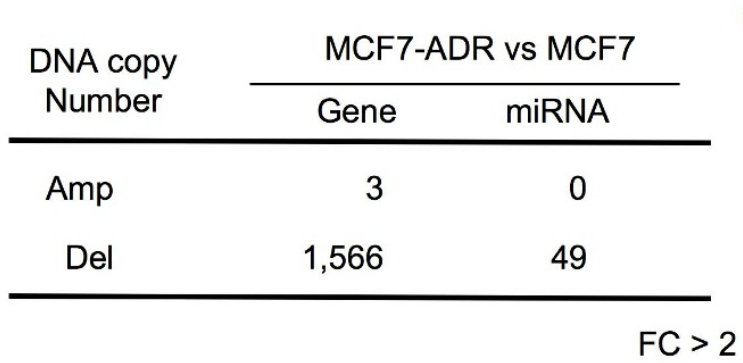

C

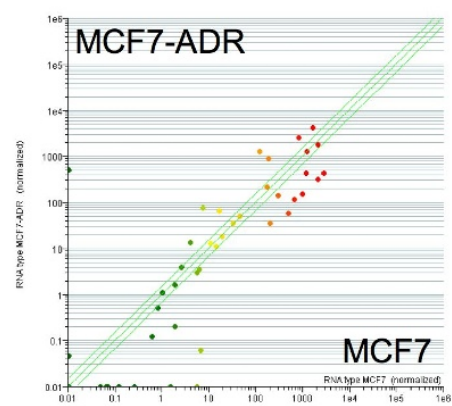

$E$

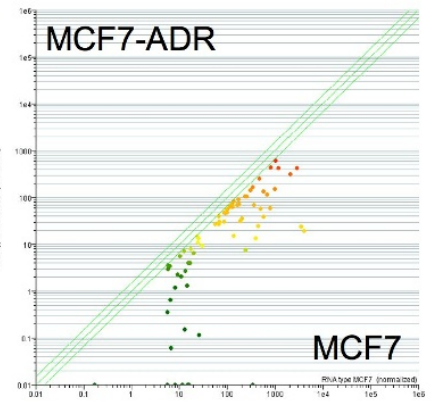

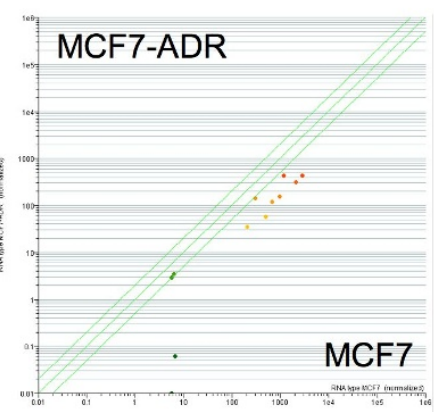

Down-

regulated Deleted

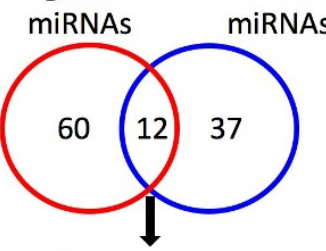

Analyze their effects on cell proliferation

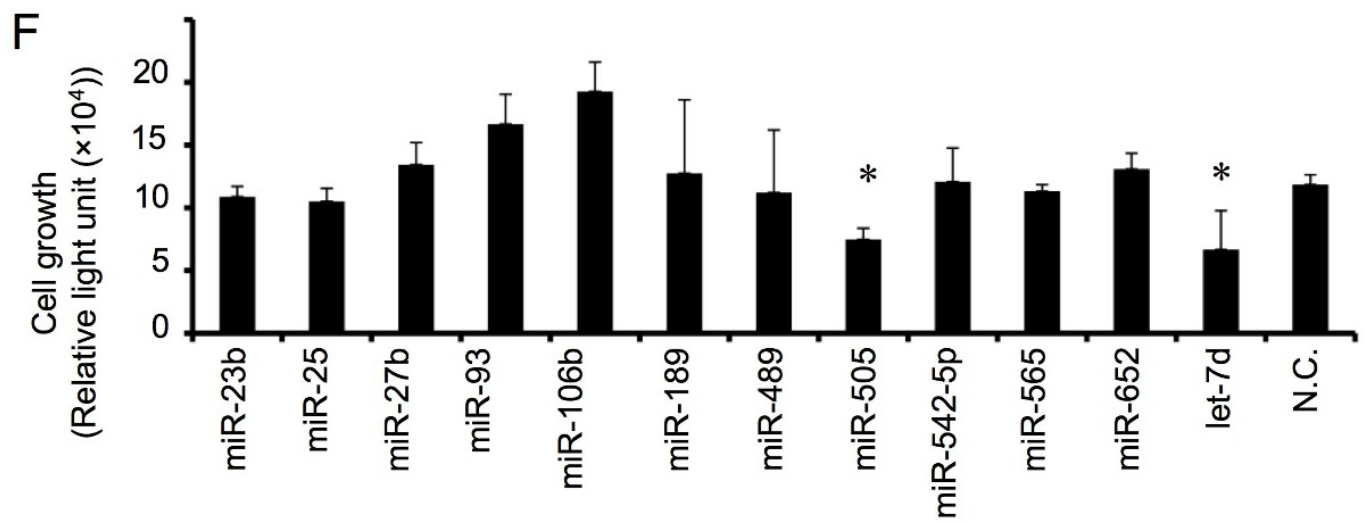

Figure 4 Screening of miRNAs responsible for drug resistance in MCF7-ADR. (A) Direct comparison of MCF7 and MCF7-ADR genomic status based aCGH. Modified Figure1B, differences in genomic status between MCF7 and MCF7-ADR are shown (FC > 2). (B) The number of genes and miRNAs located on the amplified or deleted genome regions in MCF7-ADR as compared with MCF7 (FC > 2). (C) Scatter plot of 49 miRNAs that locates in the deleted genomic regions in MCF7-ADR. (D) Scatter plot of 72 miRNAs whose expression was down-regulated in MCF7-ADR when compared with MCF7. (E) Twelve miRNAs (miR-23b, miR-25, miR-27b, miR-93, miR-106b, miR-189, miR-489, miR-505, miR-542-5p, miR-565, miR-652 and let-7d), which are overlapped between deleted and down-regulated in MCF7-ADR, are candidates responsible for drug resistance in MCF7-ADR. (F) Transfection analysis of selected 12 miRNAs in MCF7-ADR-Luc, which stably express luciferase. All miRNAs were transfected at $20 \mathrm{nM}$. Seventy-two hours after transfection, cell growth was estimated by luciferase activity in MCF7-ADR-Luc cells ( $n=3-6$ per group). $P<0.05$ 
status was deleted in MCF7-ADR cells as compared to MCF7. Expression levels of 72 miRNAs were significantly down-regulated ( $\mathrm{p}<0.05$, Additional File 7 Table S3 and Figure 4D) and 49 miRNAs (Additional File 8 Table S4 and Figure $4 \mathrm{C})$ were located in deleted regions $(\mathrm{FC}>2)$ in MCF7-ADR cells. Twelve miRNAs were overlapped between the 72 down-regulated miRNAs and 49 deleted miRNAs (Table 1 and Figure 4E).

To examine the functions of these miRNAs, we tested the effects of 12 miRNAs on cell proliferation in MCF7-ADR cells. The 12 miRNAs (miR-23b, miR-25, miR-27b, miR93, miR-106b, miR-189, miR-489, miR-505, miR-542-5p, miR-565, miR-652, and let-7d) were transfected into MCF7-ADR-Luc cells (Figure 4F). Interestingly, miR-25, miR-93, and miR-106b are known as polycistronic miRNAs [19] and their expression and genomic region were coincidently changed between MCF7-ADR and MCF7 (Additional File 9 Figure. S5). Consistent with previous report, transfection with miR-93 and miR-106b promoted cell proliferation as compared with negative control miRNA, suggesting that they actually act as oncogenic miRNAs $[19,20]$. Inversely, transfection of miR-505 and let-7d inhibited the cell proliferation of MCF7-ADR-Luc cells. Let-7 family is a well known tumor suppressive miRNA as described in many reports [21-23]. Inhibitory effects of cell growth by miR-505 and let-7d transfection are at similar level (Figure 4F). These data suggest that miR-505 is a novel tumor suppressive miRNA and plays a role in the regulation of cell proliferation similar to let-7d.

\section{miR-505 inhibits cell growth by inducing apoptotic cell death in MCF7-ADR cells}

Since transfection of miR-505 showed the inhibition of cell proliferation effectively and significantly (Figure 4F and $5 \mathrm{~A}$ ), we focused on miR-505 to evaluate its molecular function in this study. From the aCGH data, genomic region of miR-505 locus in MCF7-ADR was deleted (Figure 5B), in contrast it was intact in MCF7. The expression level of miR-505 was also decreased by realtime RT-PCR analysis in MCF7 and MCF7-ADR cells (Figure $5 \mathrm{C}$ ). To further examine the mechanism of cell growth inhibition, we sought to check whether miR-505 is responsible for cell apoptosis in MCF7-ADR cells. A mature form of miR-505 was transfected into MCF7ADR cells in the presence or absence of DOC (1 nM), as MCF7-ADR cells are resistant to DOC, and caspase-7 activity was measured to estimate apoptotic cell death in MCF7-ADR. The results of the caspase-7 assay indicated that transfection of miR-505 with DOC resulted in a marked induction of apoptosis $(p<0.05$, Figure 5D), although no significant difference was seen in the samples without DOC. We validated this result by counting the Hoechst-stained cells showing apoptotic nuclear condensation and fragmentation and found that significantly higher apoptotic cell death was observed in cells with miR-505 than in control miRNA ( $p<0.05$, Figure $5 \mathrm{E}$ and $5 \mathrm{~F}$ ). Taken together, we concluded that transfection of miR-505 inhibit the growth of drug resistance cells, MCF7-ADR, through the inducing apoptosis.

\section{Akt3, correlates inversely with miR-505 expression, modulates drug sensitivity}

It has been already known that drug resistance in cancer cells was an acquired characteristic by activation of multiple drug resistance-responsible genes. To investigate what kind of the genes are responsible for the drug sensivity by miR-505 induce gene suppression, we combined gene expression data and gene ontology (Figure 6A). As for gene expression data, since the expression level of miRNA-regulating genes was up-regulated when miRNA expression was lower in MCF7-ADR than in MCF7 cells, up-regulated genes judged by the T-test $(1,758$ genes, Additional File 10 Table S5) were selected as candidates of miR-505. As miR-505-targeted genes, apoptosis-related genes (153 genes, Additional File 11 Table S6) were chosen using a database (KEGG web site, http://www.genome.

Table 1 Selected 12 miRNAs

\begin{tabular}{|c|c|c|c|c|}
\hline Name & MCF7-ADR/MCF7 & Chromosome & Start & Stop \\
\hline hsa-miR-565 & 0.48 & 3 & 45705468 & 45705564 \\
\hline hsa-miR-489 & 0.01 & 7 & 92951184 & 92951267 \\
\hline hsa-miR-25 & 0.16 & 7 & 99529119 & 99529202 \\
\hline hsa-miR-93 & 0.15 & 7 & 99529327 & 99529406 \\
\hline hsa-miR-106b & 0.15 & 7 & 99529552 & 99529633 \\
\hline hsa-let-7d & 0.37 & 9 & 95980937 & 95981023 \\
\hline hsa-miR-23b & 0.18 & 9 & 96887311 & 96887407 \\
\hline hsa-miR-27b & 0.12 & 9 & 96887548 & 96887644 \\
\hline hsa-miR-189 (miR-24) & 0.00 & 9 & 96888124 & 96888191 \\
\hline hsa-miR-652 & 0.18 & $x$ & 109185213 & 109185310 \\
\hline hsa-miR-542-5p & 0.56 & $x$ & 133501037 & 133505133 \\
\hline hsa-miR-505 & 0.53 & $x$ & 138833973 & 138834056 \\
\hline
\end{tabular}




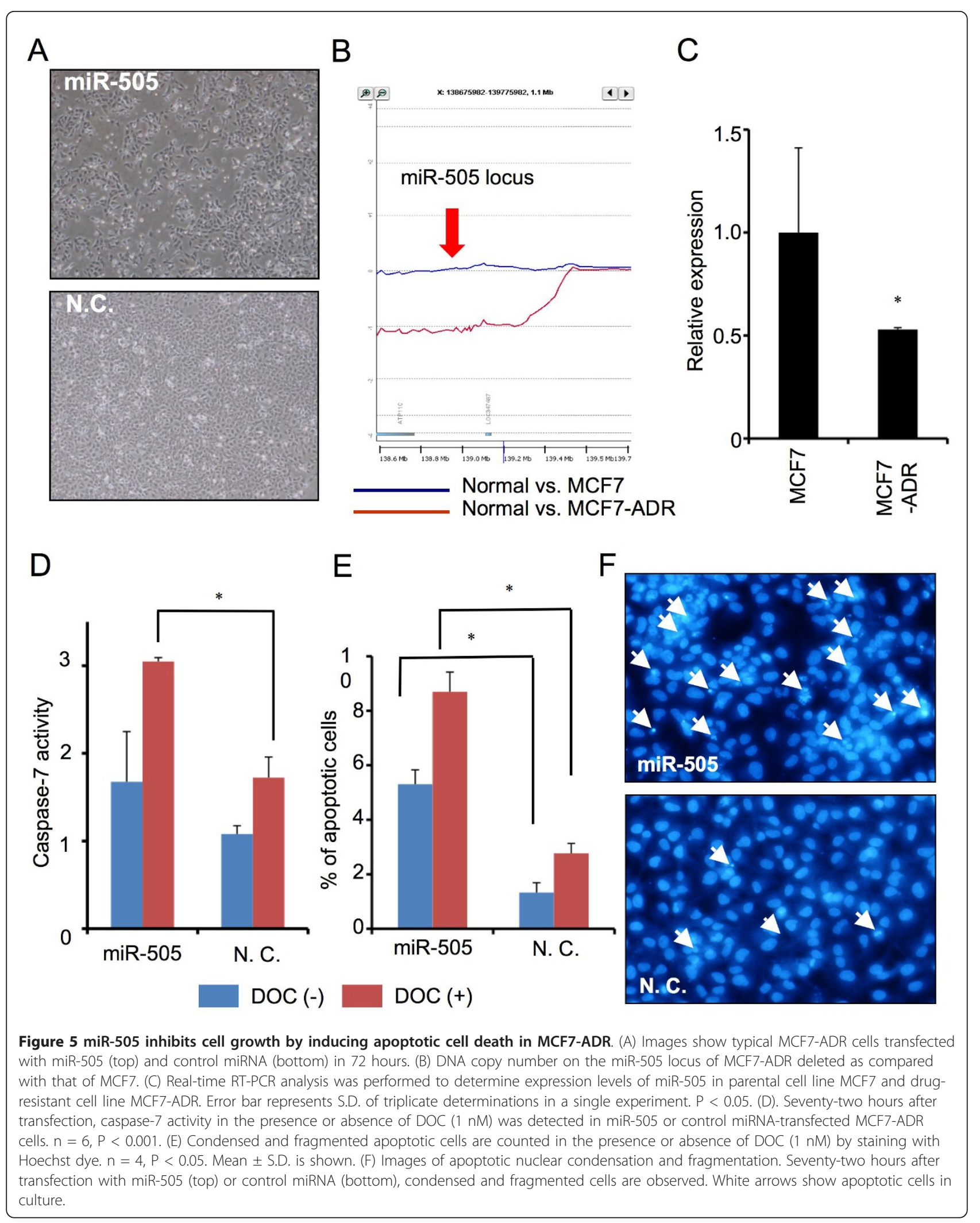


A

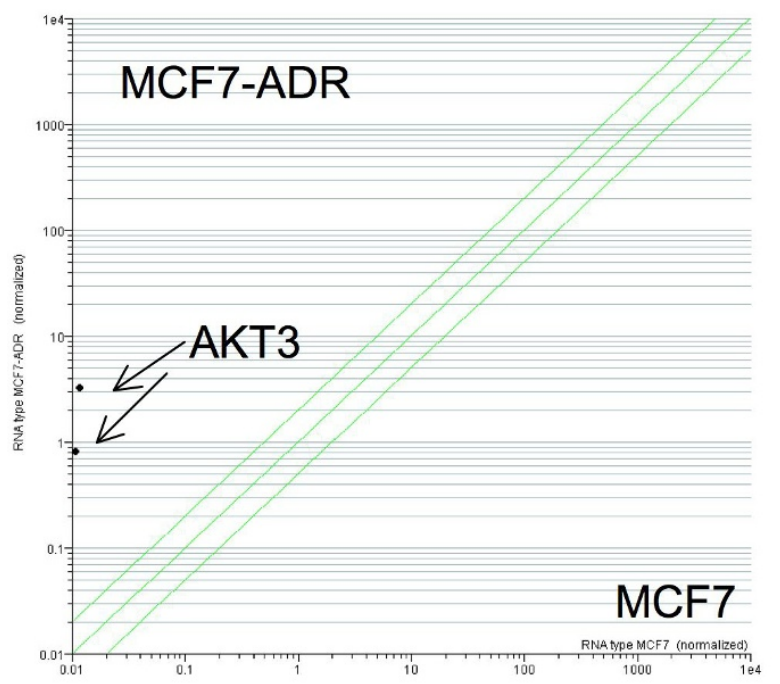

C

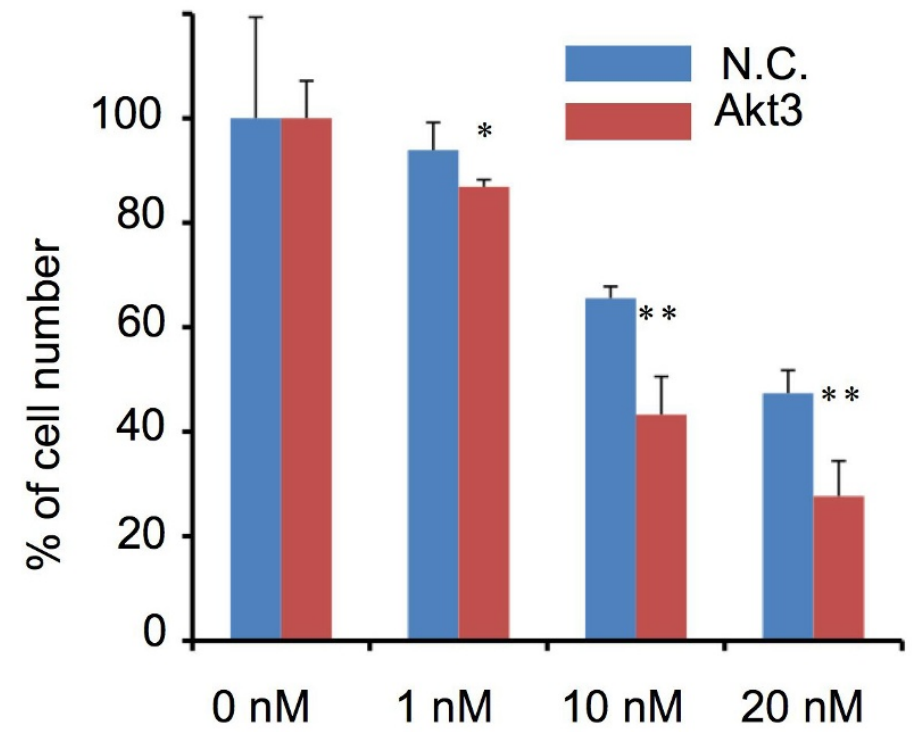

Figure 6 Akt3, whose expression was inversely correlated with miR-505, is associated with drug resistance in MCF7-ADR cells. (A) Scatter plot of 2 probes of Akt3 genes that up-regulated in MCF7-ADR cells. (B) Real-time RT-PCR analysis for Akt3 in miR-505 or control miRNAtransfected cells. Seventy-two hours after transfection with miR-505 or control miRNA, Akt3 expression levels were determined. Expression levels were normalized to GAPDH expression levels. $N=9$, mean \pm S.D. is shown. (C) Down-regulation of Akt3 induced cell growth arrest in MCF7-ADR cells at 1,10 and $20 \mathrm{nM}$ DOC conditions. Cell growth was calculated by luciferase activity. $n=3,{ }^{*}, P<0.05 .{ }^{* *}, 0.01$. 
$\mathrm{jp} / \mathrm{kegg} /$ ) because transfection of miR-505 induced apoptotic cell death in MCF7-ADR-Luc cells. By combining these data, we postulated that Akt3 gene is candidate of miR505-regulating gene, which is responsible for the drug resistance in breast cancer cell (Figure 6A). Notably, several studies have reported that Akt3 promotes melanoma development [24] and that the down-regulation of Akt3 distinctly inhibited the proliferation of ovarian cancer cell lines by slowing G2-M phase transition [25]. Given this evidence and the observed phenotype in miR-505-transfected MCF7-ADR-Luc cells, we sought to determine whether Akt 3 was a target of miR-505 or not. As shown in Figure $6 \mathrm{~B}$, decrease in relative gene expression was observed with miR-505 in MCF7-ADR-Luc cells, suggesting that miR-505 suppresses the gene expression of Akt3. However, we found that miR-505 could not bind to the 3'UTR of Akt3 gene (Additional File 12 Figure. S6), indicating that down-regulation of Akt3 after miR-505 overexpression was caused by indirect effect of miR-505mediated gene suppression. Finally, transfection of Akt3 siRNA was conducted to examine whether down-regulation of the Akt3 gene induced cell growth arrest in the presence or absence of DOC. Three days after transfection, the expression of Akt3 was clearly suppressed (Additional File 13 Figure. S7), and cell growth rates were assayed with or without 1,10 , and $20 \mathrm{nM}$ DOC conditions. A slight decrease in cell growth was observed with $1 \mathrm{nM}$ DOC condition, and more remarkable decreases was detected with 10 and $20 \mathrm{nM}$ DOC conditions in Akt3 siRNA-transfected MCF7-ADR cells than in control siRNA-transfected cells (Figure 6C). Therefore, our data show that Akt3, whose expression is correlated conversely with miR-505, regulates DOC sensitivity in MCF7-ADR cells.

\section{Discussion}

According to recent high-throughput analyses of both coding and non-coding genes, cancer progression is caused by genetic alteration involving structural and expression abnormalities of oncogenes and tumor suppressor genes $[6,26]$. In this study, we performed an integrated genomic analysis to link miRNA expression data to aCGH and gene expression microarray, using the parental cell line MCF7 and the drug-resistant cell line MCF7-ADR, to examine the molecular mechanism governing drug resistance in breast cancer. We found that the expression of miR-505 was down-regulated, and its genomic region was deleted in MCF7-ADR cells, which provided evidence that miR-505 was a tumor suppressive miRNA and had a pivotal role for inducing apoptosis in drug resistant cancer cells. In addition, by using the data of gene expression and bioinformatics analysis (gene function), our data identified Akt3 whose expression was conversely correlated with miR-505, which modulated drug sensitivity in MCF7-ADR.

Akt is a homolog of the retroviral oncogene v-Akt, which is ubiquitously expressed and has 3 members; Akt1, Akt2, and Akt3 [27]. Downstream genes of the Akt signal pathway modulate the cell cycle, DNA repair, and nitric oxide production. Moreover, Akt inhibits apoptotic cell death by inactivation of a key apoptotic molecule and is broadly activated in various kinds of cancer. Importantly, the Akt signal pathway is tightly related to drug resistance in cancer. Several studies have reported that inactivation of Akt promotes drug-induced apoptosis $[28,29]$. Therefore, inhibition of Akt3 is a therapeutic strategy for cancers by inducing apoptotic cell death and reversing drug resistance. However, our results showed that inhibition of Akt3 was less effective than transfection of miR-505 in cell growth arrest. A simple explanation of a low effect might be that miRNA could modulate the expression of a large number of downstream target genes in a highly orchestrated manner to control apoptosis and cell cycle processes

Concerning the variations in the DNA copy numbers and genomic aberrations, several reports have shown the deletions of miRNAs that act as tumor suppressors, namely miR-15, miR-16, and miR-34a. They are observed in cancer, and down-regulation of these miRNAs contributed to cancer progression, indicating that variations in DNA copy numbers are closely associated with miRNA expression and carcinogenesis $[9,10]$. Meanwhile, several data provided evidences that miRNA expressions were regulated by epigenetic modifications, such as DNA hypomethylation and hypermethylation. It has been demonstrated that miR-342 was methylated in colorectal cancer and the reconstitution of miR-342 induced apoptosis in a colorectal cancer cell line [30]. A recent study showed that miR-127, which was embedded in a CpG island, was expressed in normal fibroblast but silenced or down-regulated in cancer cells. The silencing of the miRNA promoter region of miR-127 was mediated by $\mathrm{CpG}$ island hypermethylation, which could be reversed by simultaneous treatment with the chromatin-modifying drugs 5-aza-2'-deoxycytidine and 4-phenylbutyric acid [31]. In addition, recent studies have shown that impaired miRNA processing contributes to a decrease in mature miRNA expression and accelerates tumorigenesis [32], and a number of groups have also revealed that miRNA expression is regulated by transcription factors and cytokines as well as coding genes [33]. In this study, we found 12 miRNAs whose expressions are down-regulated and their genomic regions are deleted in MCF7-ADR. Interestingly, some of them, such as miR25-93-106b and miR-23b-27b-189, are located in close proximity and their expressions are 
expected to be regulated by the same transcriptional regulators. Curiously, miR-23b-27b-189 is localized on the Ch9q22.3, and $\mathrm{LOH}$ of this region is strongly correlated with cancer progression and lymph node metastasis [34-36]. In our assay we could not observe any significant differences, however, they could be related to malignancy in different aspects $[37,38]$.

Pathway analysis, which was based on miRNA target prediction, proved that differentially-expressed miRNA cooperatively regulated a large number of signaling pathways, including Wnt, insulin, EGFR1, MAPK and TGF- $\beta$ receptor, which are relevant to drug resistance as well as tumorigenesis. Concerning the Wnt signaling pathway, it has been reported that activation of the $\mathrm{Wnt} / \beta$-catenin pathway plays critical roles in establishment of MLL leukemic stem cells and conferring drug-resistant properties [39]. Additionally, activation of Wnt/beta-catenin signaling in plasma cells induced chemoresistance [40], and RNAi-mediated gene silencing of $\beta$-catenin negatively regulated drug-induced apoptosis [41]. Therefore, Wnt/ $\beta$-catenin signaling pathway would be a potential therapeutic target to sensitize drug-resistant cancer cell. Furthermore, other pathways were also reported to be associated with drug resistance and apoptosis. Sequential treatment of TGF- $\beta$ induced MDR1 expression in rat hepatocytes [42]. In contrast, TGF- $\beta$ also induces apoptotic cell death in hepatocytes and activation of the MAPK/ ERK pathway confers resistance to TGF- $\beta$-induced cell death [43]. Our findings showed that a lot of pathways were commonly enriched in up- and down-regulated miRNA targets, however, it is hard to decide whether these pathways are positively or negatively regulated in MCF7-ADR, because a large number of target candidates exist in each signaling pathway. Further investigation such as systems biology would be needed to clarify this point.

We believe that the integrative genomic analyses as described here have a huge potential to fundamentally understand transcriptional regulatory networks and identify the novel molecular targets for therapy in the field of cancer biology. By integrating array data and bioinformatics, it could be possible to expeditiously explore the key molecule in the all aspects of pathophysiology. Our studies by means of an integrated genomic analysis not only identified miR-505 as a tumor suppressive miRNA that inhibited cell proliferation by inducing apoptotic cell death but also, more broadly highlighted that various genes and miRNAs orchestrate to temper the drug resistance by intricately controlling genomic status, gene and miRNA expression in cancer cells. Thus, it would be a useful approach to accelerate the understanding of cancer genetics and discover the key targets for diagnosis, prognosis and therapy.

\section{Additional material}

Additional file 1: Table S1. Primer list for real-time PCR.

Additional file 2: Figure. S1. Microarray analysis of gene expression and miRNA in MCF7-ADR and MCF7. (A) Scatter plot of gene expression. 41, 000 probes $(n=3)$. (B) Scatter plot of miRNA expression. 470 probes $(n=$ 2).

Additional file 3: Figure. S2. Validation of accuracy of aCGH in MCF7 and MCF7-ADR. (A) aCGH analysis of MCF7. (B) aCGH analysis of MCF7ADR. For each sample, the experiment was repeated once, wherein the dye was reversed between the experimental and the reference sample, in order to account for dye-incorporation bias. An aberration filter was set at 2 for the minimum number of probe region and 1 for minimum absolute average $\log 2$ ratio for regions in the $\mathrm{CGH}$ Analytics to reduce false positives.

Additional file 4: Figure. S3. aCGH analysis of MCF7 and MCF7-ADR as compared with normal human female genome. (A) Blue line shows normal vs. MCF7, and red line shows normal vs. MCF7-ADR (top). Amplified or deleted genome regions (fold change $>2$ ) are highlighted (bottom). (B) The numbers of genes and miRNAs located on the amplified or deleted genome regions ( $F C>2$ ).

Additional file 5: Table S2. Up and Down miRNA target gene related pathways.

Additional file 6: Figure. S4. TGF- $\beta$ signaling pathway. Seventy-four miRNA-targeted genes are plotted in TGF- $\beta$ signaling pathway map (left), 32 miRNA-targeted genes are plotted (right).

Additional file 7: Table S3. List of down-regulated miRNAs in MCF7ADR.

Additional file 8: Table S4. List of miRNAs located in genome deletion regions in MCF7-ADR.

Additional file 9: Figure. S5. Polycistronic miRNAs; miR-106-25 cluster. miR-106-25 cluster is located on the deleted genomic region, and the expression is coincidently downregulated.

Additional file 10: Table S5. List of up-regulated genes in MCF7-ADR judged by T-test in comparison with MCF7.

Additional file 11: Table S6. List of genes accosiated with apoptosis (KEGG web site).

Additional file 12: Figure. S6. The 3'-UTR assay of Akt3 by miR-505 in MCF7-ADR cells and HEK293 cells. (A) MCF7-ADR cells and (B) HEK293 cells were co-transfected with pre-miR-505 or pre-NC and the psi-Akt3_1 or with psi-Akt3_2. After 48 h, luciferase activities were measured. n.s. represents not significant.

Additional file 13: Figure. S7. Real-time RT-PCR analysis of Akt3 gene by transfection of siRNA in MCF7-ADR cells. Real-time RT-PCR analysis was performed to examine Akt3 from RNA extracted from MCF7-ADR cells transfected with either Akt3 siRNA or negative control siRNA. Akt3 expression levels were normalized to GAPDH expression levels. The mean $\pm S$. D. of results from triplicate transfections is shown. Results represent the mean \pm S. D. $(n=3)$. Since Akt3 siRNA-1 was most effectively inhibited the expression of Akt3 genes, it was used for the analysis of cell growth arrest.

\section{Acknowledgements}

This work was supported in part by a Grant-in-aid for the Third-Term Comprehensive 10-Year Strategy for Cancer Control, a Grant-in-Aid for Scientific Research on Priority Areas Cancer from the Ministry of Education, Culture, Sports, Science and Technology, and the Program for Promotion of Fundamental Studies in Health Sciences of the National Institute of Biomedical Innovation (NiBio), and a Takeda Science Foundation, and the Japan Society for the Promotion of Science (JSPS) through its "Funding Program for World-Leading Innovative R\&D on Science and Technology (FIRST Program)", initiated by the Council for Science and Technology Policy (CSTP). We thank Ayako Inoue for excellent technical assistance. 


\section{Author details}

'Division of Molecular and Cellular Medicine, National Cancer Center Research Institute, 1-1, Tsukiji, 5-chome, Chuo-ku, Tokyo 104-0045, Japan. ${ }^{2}$ Major in Integrative Bioscience and Biomedical Engineering, Graduate School of Science and Engineering, Waseda University, Nishi-waseda 1-6-1, Shinjuku-ku, Tokyo, 169-8050, Japan. ${ }^{3}$ Agilent Technologies Japan Ltd., 9-1, Takakura-cho, Hachioji-shi, Tokyo, 192-8510, Japan. ${ }^{4}$ Research Fellow of the Japan Society for the Promotion of Science (JSPS) 8 Ichibancho, Chiyoda-ku, Tokyo 102-8472, Japan.

\section{Authors' contributions}

YYa, YYo, KM, RT, and FT carried out the experimental work, YYa, KM, TT, RH and YF provided data analysis, YYa, TK, NK and TO designed the study and YYa, NK and TO participated in writing the paper. All authors read and approved the manuscript.

\section{Competing interests}

The authors declare that they have no conflict of interest. $\mathrm{KM}, \mathrm{TT}, \mathrm{RH}$, and YF are Agilent employees.

Received: 13 June 2011 Accepted: 3 November 2011

Published: 3 November 2011

\section{References}

1. Tsuruo T, Naito M, Tomida A, Fujita N, Mashima T, Sakamoto H, Haga N: Molecular targeting therapy of cancer: drug resistance, apoptosis and survival signal. Cancer Sci 2003, 94:15-21.

2. Leslie EM, Deeley RG, Cole SP: Toxicological relevance of the multidrug resistance protein 1, MRP1 (ABCC1) and related transporters. Toxicology 2001, 167:3-23.

3. Renes J, de Vries EG, Jansen PL, Muller M: The (patho)physiological functions of the MRP family. Drug Resist Updat 2000, 3:289-302.

4. Leonessa F, Clarke R: ATP binding cassette transporters and drug resistance in breast cancer. Endocr Relat Cancer 2003, 10:43-73.

5. Ambros V: The functions of animal microRNAs. Nature 2004, 431:350-355.

6. Esquela-Kerscher A, Slack FJ: Oncomirs - microRNAs with a role in cancer. Nat Rev Cancer 2006, 6:259-269.

7. Bartel DP: MicroRNAs: genomics, biogenesis, mechanism, and function. Cell 2004, 116:281-297.

8. Calin GA, Croce CM: Chromosomal rearrangements and microRNAs: a new cancer link with clinical implications. J Clin Invest 2007, 117:2059-2066.

9. Cimmino A, Calin GA, Fabbri M, lorio MV, Ferracin M, Shimizu M, Wojcik SE, Aqeilan Rl, Zupo S, Dono M, Rassenti L, Alder H, Volinia S, Liu CG, Kipps TJ, Negrini M, Croce CM: miR-15 and miR-16 induce apoptosis by targeting BCL2. Proc Natl Acad Sci USA 2005, 102:13944-13949.

10. Wei JS, Song YK, Durinck S, Chen QR, Cheuk AT, Tsang P, Zhang Q, Thiele CJ, Slack A, Shohet J, Khan J: The MYCN oncogene is a direct target of miR-34a. Oncogene 2008, 27:5204-5213.

11. Calin GA, Sevignani C, Dumitru CD, Hyslop T, Noch E, Yendamuri S, Shimizu M, Rattan S, Bullrich F, Negrini M, Croce CM: Human microRNA genes are frequently located at fragile sites and genomic regions involved in cancers. Proc Natl Acad Sci USA 2004, 101:2999-3004.

12. Imao-Koizumi K, Matoba R, Ueno N, Kim SJ, Ando A, Miyoshi Y, Maeda E, Noguchi S, Kato K: Prediction of docetaxel response in human breast cancer by gene expression profiling. J Clin Oncol 2005, 23:422-431.

13. Honma K, Iwao-Koizumi K, Takeshita F, Yamamoto Y, Yoshida T, Nishio K, Nagahara S, Kato K, Ochiya T: RPN2 gene confers docetaxel resistance in breast cancer. Nat Med 2008, 14:939-948.

14. Lipson D, Aumann Y, Ben-Dor A, Linial N, Yakhini Z: Efficient calculation of interval scores for DNA copy number data analysis. J Comput Biol 2006, 13:215-228.

15. Wang $H$, Ach RA, Curry B: Direct and sensitive miRNA profiling from lowinput total RNA. Rna 2007, 13:151-159.

16. Ma S, Tang KH, Chan YP, Lee TK, Kwan PS, Castilho A, Ng I, Man K, Wong N, To KF, Zheng BJ, Lai PB, Lo CM, Chan KW, Guan XY: miR-130b Promotes CD133(+) liver tumor-initiating cell growth and self-renewal via tumor protein 53-induced nuclear protein 1. Cell Stem Cell 2010, 7:694-707.

17. Gironella M, Seux M, Xie MJ, Cano C, Tomasini R, Gommeaux J, Garcia S, Nowak J, Yeung ML, Jeang KT, Chaix A, Fazli L, Motoo Y, Wang Q, Rocchi P, Russo A, Gleave M, Dagorn JC, lovanna JL, Carrier A, Pébusque MJ,
Dusetti NJ: Tumor protein 53-induced nuclear protein 1 expression is repressed by miR-155, and its restoration inhibits pancreatic tumor development. Proc Natl Acad Sci USA 2007, 104:16170-16175.

18. Ito Y, Motoo Y, Yoshida H, lovanna JL, Takamura Y, Miya A, Kuma K, Miyauchi A: Decreased expression of tumor protein p53-induced nuclear protein 1 (TP53INP1) in breast carcinoma. Anticancer Res 2006, 26:4391-4395.

19. He L, Thomson JM, Hemann MT, Hernando-Monge E, Mu D, Goodson S, Powers S, Cordon-Cardo C, Lowe SW, Hannon GJ, Hammond SM: A microRNA polycistron as a potential human oncogene. Nature 2005, 435:828-833.

20. Sampath D, Calin GA, Puduvalli VK, Gopisetty G, Taccioli C, Liu CG, Ewald B, Liu C, Keating MJ, Plunkett W: Specific activation of microRNA106b enables the p73 apoptotic response in chronic lymphocytic leukemia by targeting the ubiquitin ligase Itch for degradation. Blood 2009, 113:3744-3753.

21. Johnson SM, Grosshans H, Shingara J, Byrom M, Jarvis R, Cheng A, Labourier E, Reinert KL, Brown D, Slack FJ: RAS is regulated by the let-7 microRNA family. Cell 2005, 120:635-647.

22. Yu F, Yao H, Zhu P, Zhang X, Pan Q, Gong C, Huang Y, Hu X, Su F, Lieberman J, Song E: let-7 regulates self renewal and tumorigenicity of breast cancer cells. Cell 2007, 131:1109-1123.

23. Mayr C, Hemann MT, Bartel DP: Disrupting the pairing between let-7 and Hmga2 enhances oncogenic transformation. Science 2007, 315:1576-1579.

24. Cheung M, Sharma A, Madhunapantula SV, Robertson GP: Akt3 and mutant V600E B-Raf cooperate to promote early melanoma development. Cancer Res 2008, 68:3429-3439.

25. Cristiano BE, Chan JC, Hannan KM, Lundie NA, Marmy-Conus NJ, Campbell IG, Phillips WA, Robbie M, Hannan RD, Pearson RB: A specific role for AKT3 in the genesis of ovarian cancer through modulation of G(2)-M phase transition. Cancer Res 2006, 66:11718-11725.

26. Calin GA, Croce CM: MicroRNA signatures in human cancers. Nat Rev Cancer 2006, 6:857-866.

27. Vivanco I, Sawyers CL: The phosphatidylinositol 3-Kinase AKT pathway in human cancer. Nat Rev Cancer 2002, 2:489-501.

28. Yuan XJ, Whang YE: PTEN sensitizes prostate cancer cells to death receptor-mediated and drug-induced apoptosis through a FADDdependent pathway. Oncogene 2002, 21:319-327.

29. Wan X, Yokoyama Y, Shinohara A, Takahashi Y, Tamaya T: PTEN augments staurosporine-induced apoptosis in PTEN-null Ishikawa cells by downregulating PI3K/Akt signaling pathway. Cell Death Differ 2002, 9:414-420.

30. Grady WM, Parkin RK, Mitchell PS, Lee JH, Kim YH, Tsuchiya KD, Washington MK, Paraskeva C, Willson JK, Kaz AM, Kroh EM, Allen A, Fritz BR, Markowitz SD, Tewari M: Epigenetic silencing of the intronic microRNA hsa-miR-342 and its host gene EVL in colorectal cancer. Oncogene 2008, 27:3880-3888.

31. Saito $Y$, Liang G, Egger G, Friedman JM, Chuang JC, Coetzee GA, Jones PA: Specific activation of microRNA-127 with downregulation of the protooncogene BCL6 by chromatin-modifying drugs in human cancer cells. Cancer Cell 2006, 9:435-443.

32. Kumar MS, Lu J, Mercer KL, Golub TR, Jacks T: Impaired microRNA processing enhances cellular transformation and tumorigenesis. Nat Genet 2007, 39:673-677.

33. Pedersen IM, Cheng G, Wieland S, Volinia S, Croce CM, Chisari FV, David M: Interferon modulation of cellular microRNAs as an antiviral mechanism. Nature 2007, 449:919-922.

34. Mitelman F, Mertens F, Johansson B: A breakpoint map of recurrent chromosomal rearrangements in human neoplasia. Nat Genet 1997 15(Spec No):417-474.

35. Simoneau M, Aboulkassim TO, LaRue H, Rousseau F, Fradet Y: Four tumor suppressor loci on chromosome $9 \mathrm{q}$ in bladder cancer: evidence for two novel candidate regions at 9q22.3 and 9q31. Oncogene 1999, 18:157-163.

36. Sinha S, Singh RK, Alam N, Roy A, Roychoudhury S, Panda CK: Alterations in candidate genes PHF2, FANCC, PTCH1 and XPA at chromosomal 9q22.3 region: pathological significance in early- and late-onset breast carcinoma. Mol Cancer 2008, 7:84.

37. Tsuchiya Y, Nakajima M, Takagi S, Taniya T, Yokoi T: MicroRNA regulates the expression of human cytochrome P450 1B1. Cancer Res 2006, 66:9090-9098. 
38. Wang Y, Rathinam R, Walch A, Alahari SK: ST14 (suppression of tumorigenicity 14) gene is a target for miR-27b, and the inhibitory effect of ST14 on cell growth is independent of miR-27b regulation. J Biol Chem 2009, 284:23094-23106.

39. Yeung J, Esposito MT, Gandillet A, Zeisig BB, Griessinger E, Bonnet D, So CW: beta-Catenin mediates the establishment and drug resistance of MLL leukemic stem cells. Cancer Cell 18:606-618.

40. Bjorklund CC, Ma W, Wang ZQ, Davis RE, Kuhn DJ, Kornblau SM, Wang M, Shah JJ, Orlowski RZ: Evidence of a Role for Activation of Wnt/\{beta\}Catenin Signaling in the Resistance of Plasma Cells to Lenalidomide. J Biol Chem 286:11009-11020.

41. Senthivinayagam S, Mishra P, Paramasivam SK, Yallapragada S, Chatterjee M, Wong L, Rana A, Rana B: Caspase-mediated cleavage of beta-catenin precedes drug-induced apoptosis in resistant cancer cells. J Biol Chem 2009, 284:13577-13588.

42. Zhang $X$, Wang $T$, Batist $G$, Tsao MS: Transforming growth factor beta 1 promotes spontaneous transformation of cultured rat liver epithelial cells. Cancer Res 1994, 54:6122-6128.

43. Caja L, Sancho P, Bertran E, Iglesias-Serret D, Gil J, Fabregat I: Overactivation of the MEK/ERK pathway in liver tumor cells confers resistance to TGF-\{beta\}-induced cell death through impairing upregulation of the NADPH oxidase NOX4. Cancer Res 2009, 69:7595-7602.

doi:10.1186/1476-4598-10-135

Cite this article as: Yamamoto et al:: An integrative genomic analysis revealed the relevance of microRNA and gene expression for drugresistance in human breast cancer cells. Molecular Cancer 2011 10:135.

\section{Submit your next manuscript to BioMed Central and take full advantage of:}

- Convenient online submission

- Thorough peer review

- No space constraints or color figure charges

- Immediate publication on acceptance

- Inclusion in PubMed, CAS, Scopus and Google Scholar

- Research which is freely available for redistribution

Submit your manuscript at www.biomedcentral.com/submit
C Biomed Central 